\title{
The role of intellectual capital in building a competitive advantage for companies from the Baltic Sea Region in the transport, shipping and logistic industry (TSL)
}

\author{
Michat Igielski ${ }^{1, *}$ \\ ${ }^{1}$ Gdynia Maritime University, Faculty of Entrepreneurship and Quality Science, 81-87 Morska St., \\ 81-225 Gdynia, Poland
}

\begin{abstract}
The purpose of this article is to define the role of intellectual capital in companies with TSL branch in building a competitive advantage in a changing economy. In addition, the author made an attempt to assess the facts of intellectual capital management in Polish enterprises and identify conditions that accompany this process. Founded research objectives will be achieved on the basis of an analysis of theoretical materials and conducted by the author, in 2017 (100 companies from the BSR from the TSL sector), empirical research. Their main objectives were: to determine the degree of the concept of human capital management in the surveyed entities, identify the main determinants of and barriers to the development of this concept, to determine the effect of application of this concept in practice while building a competitive advantage. The study was designed as a standard general questionnaire describing the audited entity, as well as individual interviews with business owners (100 persons) and managers at various levels (300 persons). Made analysis showed the role of intellectual capital in building a competitive advantage in the surveyed enterprises - mainly in areas related to raising and maintaining the quality of services and the optimization of the employed staff.
\end{abstract}

\section{Introduction}

The changes that accompany economic transformations, forced the company to adapt to the changing conditions of the competition - they bring to these new challenges. In the twenty-first century product no longer plays such a large role in the process of building a competitive advantage because of its features can be easily copied and transferred to other products of the production. Today, the strength of the offered products and services determines the knowledge, which was used for their creation.

It also means that companies must adopt in every area of activity principle of the leading role of the client. This is the basic element of a comprehensive approach to quality $[1]$.

\footnotetext{
* Corresponding author: m.igielski@wpit.am.gdymia.pl
} 
Therefore, in the process of building a competitive advantage in the market it is the most important component of the intellectual. As the main factors driving the economy and the middle ground for success in the twenty-first century is called the wealth of the organization or its treasure [2]. In the literature, the term is also called intellectual assets, knowledge assets and intellectual property.

In the recent period there is also a lot of theoretical models and the concept of intellectual capital management. Unfortunately, there is no uniform standards and opinions concerning the tool identification, measurement and resource productivity assets. This creates a major barrier to implement them in practice - has an impact on the level of efficiency and market competitiveness of modern enterprises. This is a big problem, because the conditions of the knowledge economy, cause that is still growing role of intangible assets, namely information, knowledge and human capital - these three elements now have a crucial impact on the growth of any business. All the boards of companies, particularly in fast-growing industries (such is the industry TSL) have to look for new opportunities to build market advantage. They depart from the traditional management methods towards those that are based on intangible assets. It is the intellectual capital is a key asset of the company, and the optimal management becomes their core competence. This leads to changes in the current business organizations based on knowledge, which focus on the management resource assets. Of course, this is the basis for the human factors, namely employees who have the knowledge, skills, experience and own internal motivation.

Therefore, the aim of this article, based on the analysis of literature and empirical research is to identify the role of intellectual capital in companies with TSL branch (operating in the Baltic Sea Region - BSR), to build a competitive advantage in such changing economic conditions. In addition, the author attempts to assess the facts of intellectual capital management in the surveyed enterprises in this industry, and identify conditions that accompany this process is very important, because it leads to building a competitive advantage based on their potential.

\section{Research methodology}

Based on studies conducted by the author's observation, he stated that the implementation of the concept of intellectual capital management in the company is conditioned on its characteristics and determinants that affect the development of all components of intellectual capital. Therefore, any investment in this share is associated with a high risk, because the capital is not owned by the company - owned by its employees and partners from outside. In this connection, the boards of many companies do not decide to implement this strategy, even though he knows how it is important to build competitive advantage. This phenomenon is confirmed carried out in 2017 a study in which 100 companies participated with TSL branch, located in the BSR. While planning the research process, the author of the study tried to reach companies from different countries, which, however, operate on the common market. That is why he chose the BSR, which ideally suited the topic of research. Besides, the author participates in many international cooperation projects in this region, he has many contacts that helped to conduct the research.

The main objective of the study was to determine the prevalence of the concept of intellectual capital management in the surveyed entities. In addition, the author wanted to indicate the main factors (including barriers), its development and define the main objectives of the use of this concept in practice.

The study was designed as a general survey of standardized, which described the tested entity and individual interviews with representatives of the management boards of 
companies (100) and managers at various levels in their employees (300 people). The author planned to use the purposeful and random sampling on the basis of information on companies from the TSL sector included in the statistical data BSR for the year 2015. Unfortunately, many companies refused to participate in the study. Therefore, the author applied the principle of selection on the basis of self-declaration of participation (he sent a question to 1500 companies whether they are interested in participating in this study). Therefore, the study sample does not have the characteristics of the whole group, and presented the results of the tests are not completely set. It is also worth noting that the reported study was completed as part of the author's own research and presented the results of further research is only a small part of them (are not entirely due to the characteristics of the development) - all will be published in a separate publication.

Among the surveyed companies were the largest group of Polish companies and companies defined as the average - with employed from 50 to 249 people. The least had a group of large enterprises - more than 250 people employed. The study did not take part smallest companies - up to 9 employees, because they have enough developed structure. At the beginning it should be noted that only 63 companies used the concept of intellectual capital management - although all the companies have given such a declaration. In Fig. 1., the author showed the exact data on the application of the concept of intellectual capital in companies that participated in the study - it also took into account their size and country of origin.

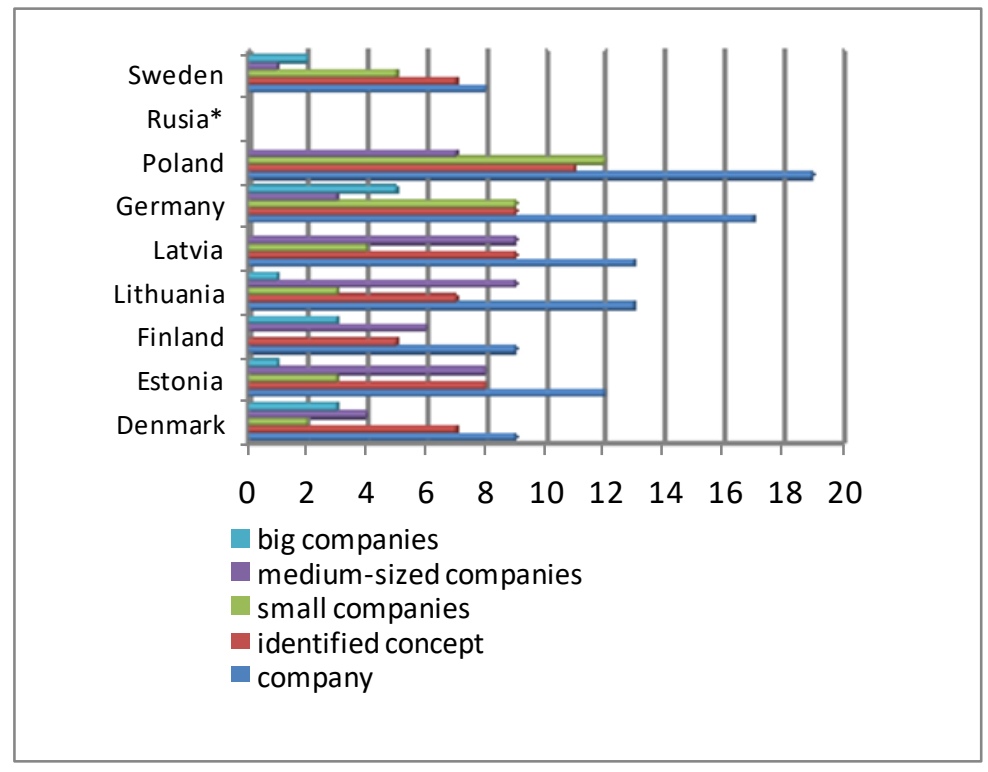

Fig. 1. Businesses participating in the study (*Russia was not taken into account).

As you can see, this concept occurs mainly in companies employing larger numbers of employees (in large companies). In the author's opinion, this is a strange phenomenon, because the implementation and management of this concept does not require an extensive structure. What is more, we can put forward a thesis that in small companies, where there are small structures, the impetus of this concept should be easier and less expensive. 


\section{The modern definition of intellectual capital}

In the available theory, and in practice, we do not find a single and consistent definition of intellectual capital. According to the author, the main reason for this situation is the fact that its components are immaterial. Therefore, if we read the literature on the subject, we can learn a lot of deadlines parts such as intangible assets, intellectual resources or hidden assets of the company.

The first information on the intellectual capital we can see already in the thirties of the last century. However, the dynamic development of this concept is at the beginning of the nineties. In practice, the economic forerunner in the field of intellectual capital management was the Swedish insurance company Skandia. The company opened a department that dealt with intellectual capital [3]. His head was L. Edvinsson. He believed that intellectual capital consists of knowledge, experience, technology, customer relationships, professional skills that give the organization a competitive advantage in the market. It is knowledge that can be converted into value. He also stated that intellectual capital consists of two components: human capital and structural capital [4].

Today, we have more and more deadlines and schedules for determining the size called intellectual capital. According to G. Roos and J. Roos intellectual capital is the sum of hidden assets that are not in the financial statements because they contain what is in the minds of employees [5]. While the H. W. A. Johnson believes that intellectual capital is the amount called goodwill, which also includes values such as brand or ability to adapt to changing competitive condition [6]. According to the definition of J. Fitz-Enz intellectual capital it includes only two categories: the intellectual property of the company and the complex combination of processes and culture - all this is connected to the various relationships and human capital [7].

In Poland, the interesting concept of intellectual capital created M. Bratnicki - this is the sum of the knowledge possessed by the people who are community enterprises and the practical ability to convert this knowledge to goodwill. He believed, too, that intellectual capital is divided into two main parts. The first is organizational capital and social capital includes the resources and processes. The second is the human capital that reflects the knowledge and skills of employees [8].

Table 1. Components of intellectual capital [9].

\begin{tabular}{|c|c|}
\hline Human capital & Capital clients (relationship) \\
\hline Education & Trademark \\
Professional qualifications & Customers \\
Knowledge associated with work & Customer loyalty \\
Professional skills & Company name \\
Predisposition psychometric & Distribution channels \\
Entrepreneurship, enthusiasm, & Cooperation with other companies \\
innovation, ability & Concession agreement \\
\multicolumn{2}{|c|}{ Organizational capital (structural) } \\
\hline \multicolumn{2}{|c|}{ Beneficial contracts } \\
\hline Intellectual property & Infrastructures assets \\
\hline Patents & Philosophy managed \\
Copyright & Organizational culture \\
Design rights & Management processes \\
Trademark & Information system \\
Outstanding service & The system links \\
Trade secret & Financial relations \\
\hline
\end{tabular}


We can therefore conclude that the intellectual capital is the property of the organization, which is based on knowledge. It is the sum of a very large number of intangible assets, which determine the market value of each company in the XXI century. In theory, but in practice, it is often referred to as the knowledge capital or intellectual matter.

Specific elements that make up the intellectual capital, the author showed in Table 1. However, it must be said that in order to effectively use this capital, every company must implement a complete system to manage all of its components.

Some authors believe that to create value for the enterprise greatest significance is the capital organization, because the value is not derived directly from the operation of any of the components of intellectual capital, only the interaction between all these elements. Even if the company that has a well developed only one or two elements of the intellectual capital, there is no possibility of transformation of intellectual capital in value.

However, according to the author, the most important in the whole process of building the intellectual capital is a component of human capital. In the twenty-first century, companies can no longer build their success only by investments in material resources and using cheap labor. Today is the people depend on the market success of modern enterprises.

To summarize the above considerations, we can conclude that the concept of intellectual capital has been designed to fully demonstrate its importance and essence in building competitive advantage. Intellectual capital, we can consider considered as an intangible asset an organization - that is, assets soft, because it has a significant impact on the value of the company and is not listed on the side of its assets. On the other hand, it must be taken into account in the management of the company, as it helps to improve the efficiency with optimal use of the available intellectual resources.

\section{Construction of competitive advantage based on intellectual capital in the industry TSL}

Contemporary TSL market in Europe is characterized by increasing competition, which forces companies to look for new methods of management - the old ones are already very effective. In this connection an important role to leverage existing intellectual capital to create and implement innovations that have become the main determinant of building a competitive advantage in the market. From this analysis we can conclude that the TSL industry in recent years has dynamic development. This is the result of the development of innovative information technology and related processes of economic globalization - it is the main driving force. This process is also enhanced: the rising costs of transportation, production and maintenance of permanent stockpiles.

Transport has become a major factor in the economic development of the BSR, since the cargo and passengers he meets most people's needs. The development of transport brings together the markets allows for increased production and economic growth. There is no world economy during its globalization, without the network of routes and transport links, which allow manufacturers, exporters and importers freely enter into contracts irrespective of the place of action. These regions of the world that do not have roads and transport points can not participate in international exchange and industrial cooperation. Without the development of transport there will be a further increase in production and an increase in social. On the other hand, transport can also be a barrier that restricts economic growth.

The main objective, which want to reach companies in the sector, is a change in the way that you want them to change in organizations that use and zarządzaniją knowledge. This process is intended to improve the flow of data and information and coordinate all activities related to the planning, operation, or making decisions. Companies need to take action and 
innovative organizations to be innovative. To summarize the main objectives of the activities carried out innovative companies in this industry are [10]:

- Increasing the efficiency of the services provided.

- Increasing customer satisfaction.

- Strategic planning.

- Increasing the flexibility and speed of decision-making processes of supply chain management.

- Increasing the innovative capacity.

Most companies do not perceive logistics innovations as absolute novelty in the way the provision of logistic services. And innovation is even a small change in the way the provision of services to clients. The observations made by the author shows that the main element of innovation in the industry TSL is striving towards management of intellectual capital and create good relationships with employed workers.

Companies that are planning to have success in today's economic market, have their activities systematically programmed and adapted to the situation. Companies that want to be competitive they must create internal flexibility that is needed to adapt to changing conditions. In this way, he reached a particular perks. Modern concepts of building competitive advantages are mainly related to the ability to use knowledge [11]. Currently, it is the search for and implementation of the relevant components of intellectual capital. However, the construction by the company a competitive advantage in the market today depends on proper connection and operation of all these elements.

Analyzing the scientific literature of the subject, we can find a lot of concepts associated with the term competitiveness. The most important of them are: competition, competitiveness or competitive advantage. Relationship that binds these three concepts best describe the character graphic in Figure 2.

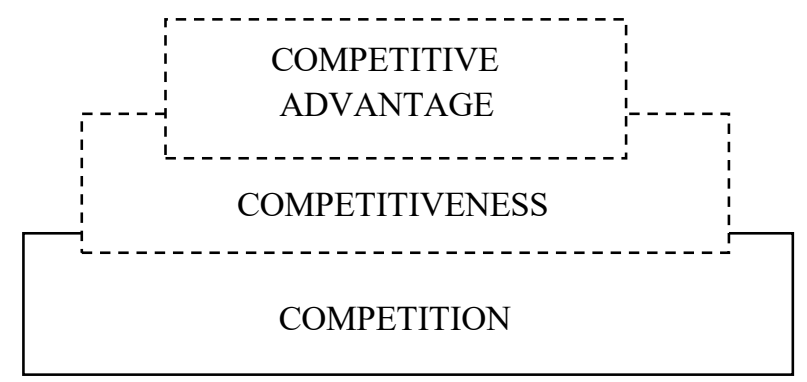

Fig. 2. The relationship between competition, competitiveness and competitive advantage [12].

The term competition can be defined as an arena in which companies compete for customers. It consists of companies in the sector, competitors and institutions governing the functioning of companies [12]. In turn, the competitiveness can be understood in different ways, depending on the interest groups. For example, competition for customers is limited to the attractiveness of the product or service, and for business owners is the whole functioning of the company [13].

As for the definition of competitive advantage believes scientists are divided. The author chose those relating to the use of resources of intellectual capital:

1. The concept is based on the resources and core competencies: its subject is not the sector and the company. Its basis are key competencies defined as skills that are crucial to the results of the company [14].

2. Contingency theory / approach: it is constantly adapting to changing environmental conditions [15]. 
3. The concept of knowledge (knowledge based competition): current knowledge is a strategic asset of the company that determines its development, survival and building a competitive advantage [15].

It says, however, to build a competitive advantage based on intellectual capital, we find the determinants that determine the intellectual potential of the company. Especially in the case of the TSL sector, which is growing very quickly and is a service - a difficult process to identify these determinants. Therefore, at the planning stage of research, the author has attempted to identify those factors (based on the analysis of materials). The author at the beginning of the shared intellectual potential of the internal and external (this is the result of the types of components) and the same share of its determinants. Through this division, we can optimize their utilization and intangible asset pooling resources to build assets that occur in different places.

Table 2. Determinants of external and internal intellectual potential of enterprises in the TSL [16].

\begin{tabular}{|c|c|}
\hline \multicolumn{2}{|r|}{ Determinants of external } \\
\hline $\begin{array}{c}\text { Segments } \\
\text { environment }\end{array}$ & \\
\hline Political & $\begin{array}{l}\text { Pro-innovation policy of the state; Legal and procedural; Stability } \\
\text { policy; Procedures supporting the innovation activities; R + D } \\
\text { policy; The level of protection of property rights; }\end{array}$ \\
\hline Social & $\begin{array}{l}\text { Availability innovation; Bureaucracy; Globalization; Location of } \\
\text { the company; Human potential; Social mobility; Quality of life; }\end{array}$ \\
\hline Economic & $\begin{array}{l}\text { The level of market competition; The growth rate of the market; } \\
\text { Exchange rate stability; Collaboration between companies; Interest } \\
\text { rates; The level of unemployment; The level of financial support }\end{array}$ \\
\hline Technology & $\begin{array}{l}\text { The rate of technology transfer; The level of technological } \\
\text { development; Advisory support and research; Infrastructure; New } \\
\text { distribution channels }\end{array}$ \\
\hline \multicolumn{2}{|r|}{ Determinants of internal } \\
\hline \multicolumn{2}{|r|}{ Material } \\
\hline \multicolumn{2}{|l|}{ Group resource } \\
\hline Property & $\begin{array}{l}\text { Technical measures; Modern technologies; Modern facilities R \& } \\
\text { D; Availability of resources }\end{array}$ \\
\hline Financial & $\begin{array}{l}\text { The ability to use external sources of financing; Capital structure; } \\
\text { The costs of the research activity; Potential corporate finance; They } \\
\text { have their own financial resources }\end{array}$ \\
\hline \multicolumn{2}{|r|}{ Immaterial } \\
\hline \multicolumn{2}{|l|}{ Group resource } \\
\hline Human capital & $\begin{array}{l}\text { Creativity of employees; Management skills; Learning ability; The } \\
\text { ability of project management; Motivating system; } \\
\text { Communication; Ability to manage risk; The size and structure of } \\
\text { employment; Productivity and employee engagement }\end{array}$ \\
\hline $\begin{array}{l}\text { Organizational } \\
\text { capital }\end{array}$ & $\begin{array}{l}\text { Organizational culture; The reaction rate changes; Our own R \& D } \\
\text { The size of the enterprise; The scale and scope of activity; The flow } \\
\text { of information; Experience in the industry; Image and brand; } \\
\text { Market position }\end{array}$ \\
\hline Relational capital & $\begin{array}{l}\text { Susceptibility to innovation; The degree of risk-benefit sharing; } \\
\text { The role of companies in the supply chain; Trust; The ability to } \\
\text { identify the needs of customers; Cooperation with scientific } \\
\text { institutions; Logistics partnership }\end{array}$ \\
\hline
\end{tabular}


Thanks to this division, we can accurately show the complexity of factors that influence the shape of the intellectual capital of companies in the TSL. In addition, we know that we have different methods and tools to manage it. Moreover, this statement is a perfect introduction to the presentation of research results.

\section{The role role of intellectual capital in TSL companies}

With reference to the earlier words, the implementation of the concept of intellectual capital management is dependent on the characteristics and determinants of the development of all its components. Therefore, investment in this type of capital associated with high risk. However, many owners and managers of companies in the TSL understand its importance for the organization and want to implement it - confirmed it carried out the study.

In Figure 4 the author presents the opinion of business owners and managers on the role of intellectual capital in their organizations. Due to the objectives of the study, the author wanted to know their opinion was compared to the traditional factors of production. Despite the fact that in some companies, this concept has not been implemented, after analyzing the information, we can conclude that the potential of intellectual assets is highly regarded in the current economic reality.

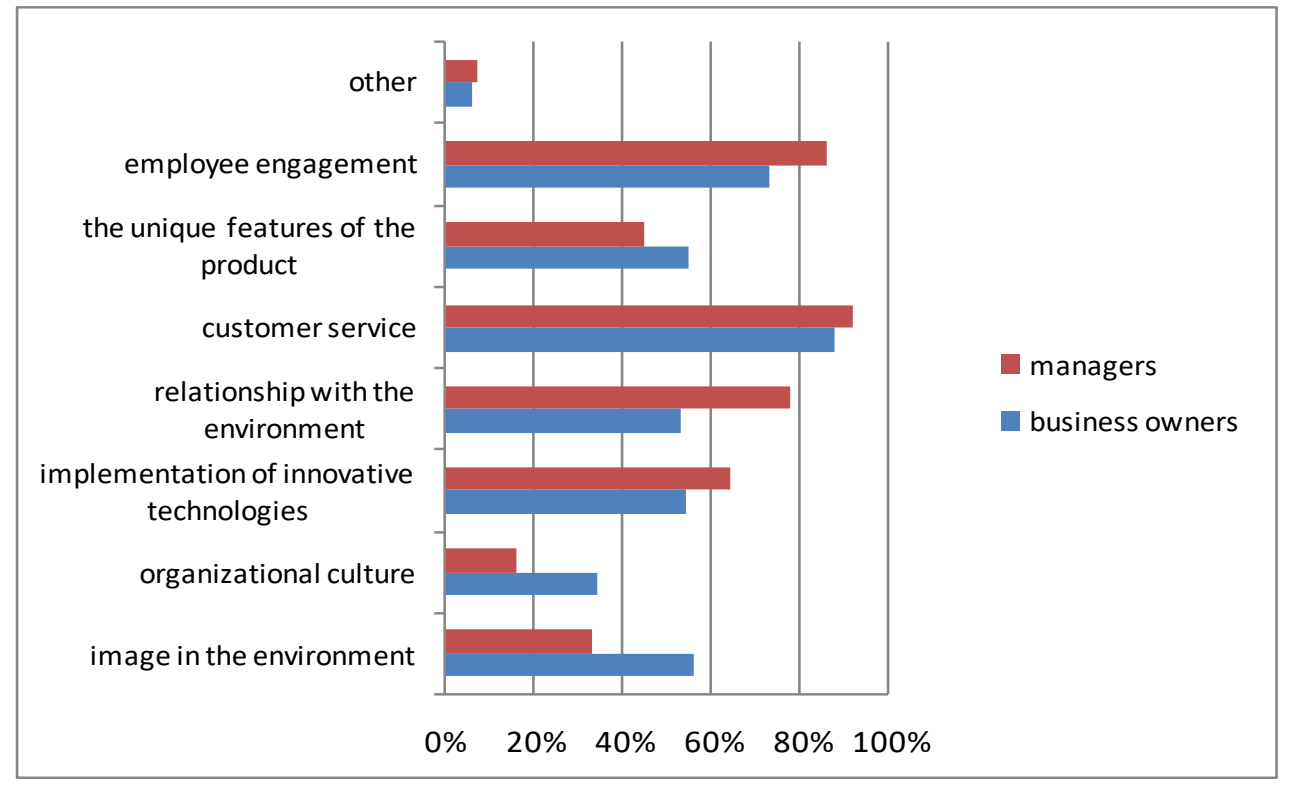

Fig. 3. The role of intellectual capital in companies which participated in the study.

Based on respondents' answers, the author has the idea that they are aware of the need to build their competitive position on the basis of investments in intangible assets. However, in this process is a lot of barriers that do not allow them to implement the concept of intellectual capital management in their organizations. These barriers could also be identified during the study, and industry representatives TSL found that mainly are: the mentality of employees, high cost, high risk, lack of funds and proper tools. The detailed distribution of responses, with the division's role-based company in the detail shown in Fig. 4. 


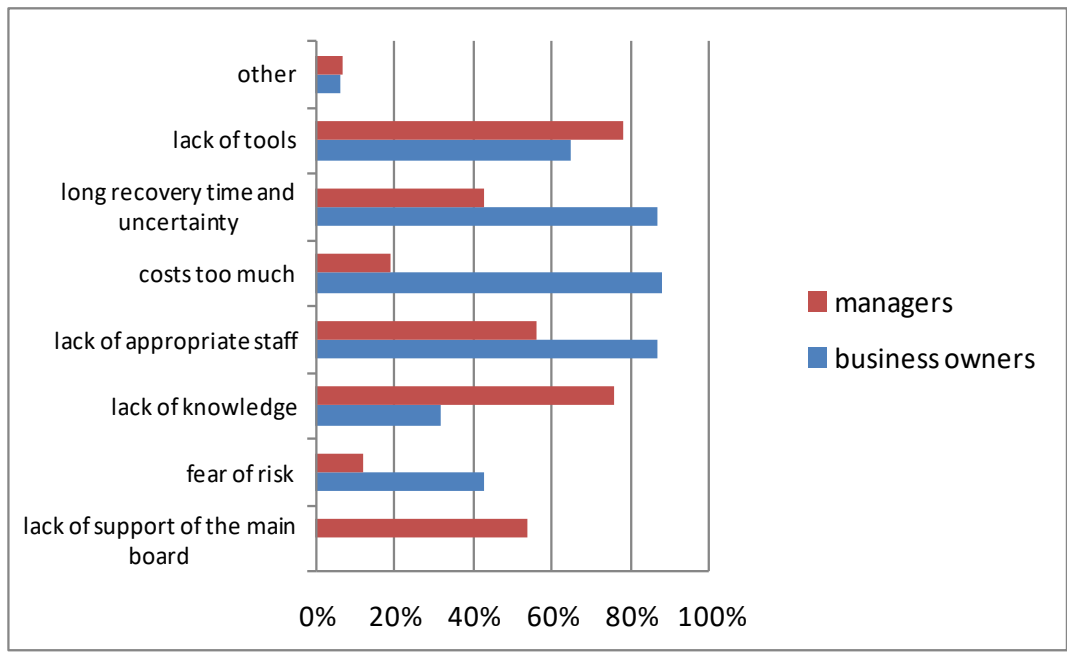

Fig. 4. Barriers to implementing the concept of intellectual capital in companies which participated in the study.

Due to the large differences characterizing these barriers, their different origins and extremely varied effects, they were assigned to 4 main categories, which are presented in Table 3.

Table 3. Categories of barriers to the implementation of the concept of intellectual capital in the companies which participated in the study.

\begin{tabular}{|c|c|}
\hline $\begin{array}{l}\text { A kind of } \\
\text { barrier }\end{array}$ & Description \\
\hline Mental barrier & $\begin{array}{c}\text { attachment heads to traditional solutions; lack of conviction about the } \\
\text { need or possibility of implementation of intellectual capital } \\
\text { management; resistance to change - organizational disorder existing } \\
\text { order, }\end{array}$ \\
\hline $\begin{array}{l}\text { Cultural } \\
\text { barrier }\end{array}$ & $\begin{array}{l}\text { lack of culture of sharing knowledge - the fear of losing current } \\
\text { position; negating the need to implement innovative solutions and } \\
\text { increase operational flexibility, do not appreciating the importance of } \\
\text { building relationships with partners outside the company, }\end{array}$ \\
\hline $\begin{array}{c}\text { Competence } \\
\text { barrier }\end{array}$ & $\begin{array}{l}\text { managers do not have the knowledge of modern management } \\
\text { concepts; managers do not know how to use modern tools to measure } \\
\text { the effectiveness of intellectual capital management; there are too } \\
\text { many concepts categorization of intellectual capital, there is no } \\
\text { standardization of tools for managing intellectual capital, }\end{array}$ \\
\hline $\begin{array}{c}\text { Organizational } \\
\text { barrier }\end{array}$ & $\begin{array}{c}\text { no information systems necessary for the smooth flow of knowledge } \\
\text { in the organization; a high turnover of employees - the loss of } \\
\text { valuable knowledge }\end{array}$ \\
\hline $\begin{array}{c}\text { Financial } \\
\text { barrier }\end{array}$ & $\begin{array}{c}\text { the pursuit of profit maximization - the lack of an investment in the } \\
\text { invisible assets; the high cost of implementation of intellectual capital } \\
\text { management }\end{array}$ \\
\hline
\end{tabular}

Equally interesting and very optimistic, they present the responses that relate to the role they must play implemented the concept of intellectual capital management in building a competitive advantage.

The answers that relate to improving the quality of services or adapt to the needs of customers, they are confirming that key people in companies have a high awareness of the role of this concept. Most of the indicated purposes is practically the same as the main 
factors shaping the competitive position in the industry TSL - detailed distribution of responses shown in Fig. 5.

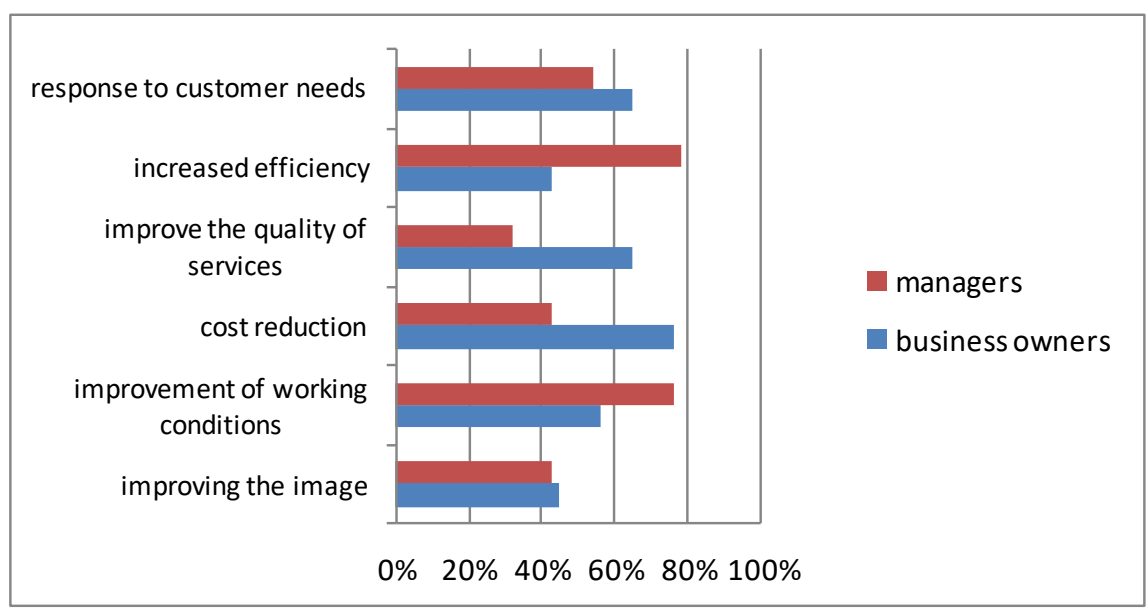

Fig. 5. Opinion of respondents on the role of the concept of intellectual capital management in building competitive advantage

In summary, based on all of the previously described theoretical considerations and the results of the study, the author states, that intangible assets in the process of building competitive advantage of companies in the TSL are already very appreciated. It is also important that business owners are aware of what can be achieved through the concept of management of intellectual capital. They also know what it depends on - business strategy, environment variables and the extent implemented the concept of intellectual capital.

In addition, we must remember that create a model of intellectual capital management in a company is not an easy process, since it must include:

- Development of strategies related to intellectual capital,

- Creation of databases on intellectual capital - acquiring and storing them in the information and knowledge.

- Permanent development of intellectual capital.

- Protection of intellectual capital.

- Permanent monitoring of intellectual capital.

However, despite these problems, we know that this concept can give a company a lot of benefits and can determine its success in the market because:

- Eliminates commit the same mistakes.

- Encourages innovative attitudes.

- Uses the accumulated knowledge, for example, for planning or execution of tasks.

- Creates an opportunity optimal use of the remaining resources.

- Creates new structures functioning in a changing environment.

- Helps to create partnerships and implement the results of R \& D.

\section{Conclusions}

Author conclude, intellectual capital is a combination and joint action of all intangible assets which companies have or are able to create using the knowledge. Most important, however, it is to use this potential to be better than the competition. Companies must strive to these resources has become their main asset market. This is very important because in 
today's market, companies can only function through flexibility and adaptation to the changing environment. The more that in the era of globalization and knowledge-based economy, traditional methods of competition are no longer guarantee the achievement of expected results. Today, companies that build competitive advantage need to adjust their internal operations to changing external conditions. All the more so if they are industries that are developing dynamically - for example, TSL industry. In these industries to grow a lot of competition, which forces each game are saved striving for optimal management. Therefore, if these companies plan to increase their effectiveness, they must use modern forms of management that are used to implement and achieve certain results.

Therefore, intellectual capital is beginning to be seen as a major factor at the macro and micro. Without it, no entity has reached the expected level of innovation. Of course, this process is accompanied by fundamental dilemmas. They relate to the type of determinants influencing the development of intellectual capital and the conditions of management. But after all, recent years have shown, the concept of intellectual capital has become a strategic management option, and affects the position of the company on the market.

\section{References}

1. Yi - W. Fan, E. Ku, The Service Industries Journal, 30/2, 207-217 (2010)

2. T.A. Stewart, Intellectual capital: The New Wealth of Organizations (Nicholas Brealey Press, Boston, 1995)

3. K. Beyer, Studia i Prace WNEiZ, 25, 243-251 (2012)

4. L. Edvinsson, Intellectual capital (PWN, Warszawa, 2001)

5. J. Rzempała, Zeszyty naukowe Uniwersytetu Szczecińskiego, 453/8, 203-219 (2007)

6. W.H.A. Johnson, International Journal of Technology Management, 4/3, 562-575 (1990)

7. J. Fitz-Enz, Profitability of investments in human capital (Oficyna Ekonomiczna, Kraków, 2001)

8. M. Bratnicki, Entrepreneurship and intellectual capital (Akademia Ekonomiczna w Katowicach, Katowice, 2001)

9. R. Dzinkowski, Financial times world accounting report, 4/2, 21-36 (1999)

10. J. Chwiećko, K. Dziekoński, Economics and Management, 2, 176-184 (2013)

11. D. Cetindamar, H. Kilitcioglu, Competitive Review: An International Business Journal, 23(1), 18-25 (2013)

12. S. Kasiewicz, Change the terms of the competitiveness of enterprises. Intellectual capital, the prospects look partners (Oficyna Ekonomiczna, Kraków, 2006)

13. J. Rzempała, Zeszyty naukowe Uniwersytetu Szczecińskiego, 453/8, 203-219 (2007)

14. G. Hamel, C.K. Prahalad,. Harvard Business Review, 82/3, 77-83 (1990)

15. J. Macias, Przegląd Organizacji, 9, 4-12 (2008)

16. M. Kruczek, E. Przybylska, Z. Żebrucki, Zeszyty naukowe Politechniki Śląskiej, 79, 209-218 (2015) 